\title{
PREPARAÇÃO EXPERIMENTAL DE SILAGEM COMO RECURSO DIDÁTICO NA DISCIPLINA DE FORRAGICULTURA NO CURSO DE MEDICINA VETERINÁRIA DO IFAM, AMAZONAS, BRASIL
}

\author{
Gabriella Noda Perdigão dos Santos ${ }^{1}$ \\ Hellen Mirian Ferreira Freitas ${ }^{1}$ \\ João Victor Amaral da Silva ${ }^{1}$ \\ Kathrinne Lopes Cruz ${ }^{1}$ \\ Klissia dos Santos Silva ${ }^{1}$ \\ Nívia Braga Vianna ${ }^{1}$ \\ Jomel Francisco dos Santos 2
}

SANTOS, G. N. P. dos; FREITAS, H. M.F.; SILVA, J. V. A. da; CRUZ, K. L.; SILVA, K. dos S.; VIANNA, N. B.; SANTOS, J. F. dos. Preparação experimental de silagem como recurso didático na disciplina de forragicultura no curso de Medicina Veterinária do IFAM, Amazonas, Brasil. Arquivos de Ciências Veterinárias e Zoologia da UNIPAR, Umuarama, v. 24, n. 1cont., e2408, 2021.

RESUMO: A silagem pode ser utilizada na alimentação de ruminantes e equídeos, sendo uma alternativa viável em épocas de estiagem. Para a produção de silagem, é importante optar por plantas forrageiras que atendam às necessidades nutritivas dos animais e que possuam características favoráveis para a conservação e aproveitamento das mesmas. Com o objetivo de preparo de um produto ensilado de qualidade, e ressaltar o uso de experimentos práticos para fins didáticos, foi realizado um ensaio demonstrativo de preparação de silagem. Neste trabalho, também foram feitas comparações de cada fase fermentativa do processo de forma visual. A metodologia empregada nesse experimento se mostrou eficaz visto os resultados obtidos em relação ao produto fabricado e a facilidade na assimilação do conteúdo por parte dos discentes, ressaltando a importância da boa conduta na produção desse alimento.

PALAVRAS-CHAVE: Ensilagem. Ensino-aprendizagem. Metodologia.

\section{EXPERIMENTAL PREPARATION OF SILAGE AS A DIDATIC RESOURCE IN THE FORAGE CROP DISCIPLINE IN THE VETERINARY MEDICINE COURSE AT IFAM, AMAZONAS, BRAZIL}

\begin{abstract}
Silage can be used to feed ruminants and equines and is a viable alternative in drought times. For silage production, it is important to choose forage plants that meet the animal nutritional needs and have favorable characteristics for their conservation and use. In order to practice and learn about the ensiling good practices, a silage preparation experiment was performed and documented in video, for didactic purposes, in the forage crop discipline. In this study, each fermentation phase of the process was visually compared. The methodology used in this experiment proved to be effective given the results obtained about the manufactured product and the ease assimilation of content by students, emphasizing the importance of good practices in this food production.
\end{abstract}

KEYWORDS: Ensiling. Methodology. Teaching-learning.

\section{PREPARACIÓN EXPERIMENTAL DE ENSILAJE COMO RECURSO DIDÁCTICO EN LA ASIGNATURA DE FORRAJE CULTURA EN EL CURSO DE MEDICINA VETERINÁRIA DE IFAM, AMAZONAS, BRASIL}

RESUMEN: El ensilaje puede ser utilizado para alimentar a los rumiantes y a los equinos y es una alternativa viable en tiempos de sequía. Para la producción de ensilaje, es importante elegir plantas forrajeras que atiendan a las necesidades nutricionales de los animales y que tengan características favorables para su conservación y aprovechamiento. Con el objetivo de preparo de un producto ensilado de calidad, y resaltar el uso de experimentos prácticos para fines didácticos, se realizó un ensayo demostrativo de preparación de ensilaje. En este trabajo, las comparaciones de cada fase de fermentación del proceso también se hicieron de manera visual. La metodología empleada en ese experimento demostró ser eficaz, dados los resultados obtenidos en relación con el producto fabricado y la facilidad de asimilación del contenido por parte de los estudiantes, destacando la importancia de la buena conducta en la producción de ese alimento.

PALABRAS CLAVE: Ensilaje. Enseñanza y aprendizaje. Metodología

DOI: https://doi.org/10.25110/arqvet.v24i1cont.2021.8181

${ }^{1}$ Discente do curso de Medicina Veterinária, Instituto Federal de Educação, Ciência e Tecnologia do Amazonas - IFAM - MANAUS/AMAZONAS BRASIL.

${ }^{2}$ Docente do curso de Medicina Veterinária, Instituto Federal de Educação, Ciência e Tecnologia do Amazonas - IFAM - MANAUS/AMAZONAS BRASIL.jomel.santos@ifam.edu.br 


\section{Introdução}

A nutrição é um importante fator para a eficiência produtiva dos animais, independente de sua aptidão, a qual deve ser equilibrada e atender todas as necessidades nutricionais (MACÊDO; SANTOS, 2019). O Brasil destacase na produção de alimentos devido ao extenso território e grande quantidade e diversidade de recursos naturais. Dessa forma, favorece o cultivo de plantas forrageiras, que se destacam como os principais alimentos oferecidos aos ruminantes e também aos equinos (DIAS-FILHO, 2014; DOMINGUES, 2009; MACÊDO; SANTOS, 2019).

Apesar dessas condições favoráveis, em determinadas áreas do país ocorre variação na produção e qualidade das forragens em decorrência dos fatores climáticos, havendo períodos com excesso e outros com escassez. Como consequência, a escassez pode causar prejuízos para o rebanho como o aumento da mortalidade, a perda de peso, além da baixa produtividade na época da seca (PEREIRA; BUENO; HERLING, 2015).

Por esses motivos, devem-se buscar alternativas e formas de fornecer alimento em quantidade e qualidade que atenda a demanda dos animais, sendo opções que supra a reduzida oferta durante o período seco do ano. E dentre as alternativas, tem-se a ensilagem que é a técnica de armazenamento de forragem ou grãos úmidos em um ambiente anaeróbico, de forma que é conservado pela acidificação (PEREIRA; BUENO; HERLING, 2015). A silagem é de grande proveito para regiões que buscam conservar o alimento durante o período de chuva, em que há excedentes, para utilizar no período de estiagem. Para manter as características químicas, físicas e o valor nutricional do alimento, é preciso manter as condições adequadas para o desenvolvimento dos microrganismos desejáveis que irão promover a fermentação, e assim, manter conservado a ensilagem, minimizando as perdas (MACÊDO; SANTOS, 2019).

A escolha da forrageira adequada é um fator muito importante, por isso é preferível as que possuam alto teor de carboidratos solúveis, matéria seca e um bom valor nutritivo para que as necessidades nutricionais do animal sejam atendidas. No Brasil, a silagem de milho é a mais conhecida e praticada, seguida do sorgo, capim-elefante e outras gramíneas forrageiras. Entretanto, é possível ensilar muitos outros produtos e subprodutos agrícolas (PEREIRA; BUENO; HERLING, 2015).

O capim popularmente conhecido como Capimelefante (Pennisetum purpureum), seguidos do milho e o sorgo, é uma das forrageiras tropicais com as melhores características para ensilar, devido a alta produtividade, grande número de variedades, adaptabilidade, facilidade de cultivo, boa palatabilidade e também aceitabilidade pelos animais (quando novo) (MOREIRA et al., 2008).

Diante do exposto, este trabalho visou reforçar a importância do uso da silagem e das boas práticas a serem adotadas durante a ensilagem, com o objetivo de preparo de um produto ensilado de qualidade. E, também, ressaltar o uso de experimentos práticos para fins didáticos, a fim de proporcionar aos alunos uma maior facilidade na assimilação do conhecimento a respeito do tema.

\section{Material e Métodos}

O experimento foi conduzido no Instituto Federal de Educação, Ciência e Tecnologia do Amazonas - Campus Manaus Zona Leste - CMZL na área do prédio do curso de Medicina Veterinária. Utilizou-se na ensilagem a planta forrageira Capim-elefante (Pennisetum purpureum) do grupo Napier Verde, com altura de $1,80 \mathrm{~m}$, colhida na capineira ao lado do prédio de Medicina Veterinária. A colheita e a picagem foram realizadas de forma manual com tamanhos de partículas de $1,6 \mathrm{~cm}$ e $20 \mathrm{~cm}$. O material triturado foi separado em amostra 1 e amostra 2 sem o uso de aditivos. $\mathrm{O}$ capim foi ensilado em mini silos com superfície transparente, ambos com capacidade de 1,5 L.

A amostra 1 apresentava superfície plana e foi compactada com as partículas de 1,6 cm, sendo vedado com plástico, tampa e fita adesiva; a amostra 2 com superfície irregular, recebeu as amostras de $20 \mathrm{~cm}$ sem compactá-las, sendo vedada de forma parcial com um furo de $2 \mathrm{~mm}$ de diâmetro na tampa. Ambos os silos foram abrigados em local arejado e cobertos com plástico preto. Posteriormente à armazenagem das amostras 1 e 2, foi acompanhado o processo fermentativo de forma macroscópica e anotado o comportamento nos dias: zero, um, cinco, 10, 17, 25, 30 e 40 após o preparo das amostras.

Após o $40^{\circ}$ dia, os silos foram abertos e observaramse os aspectos internos de cor, textura e cheiro da silagem. Ainda, realizou-se uma cultura com plaqueamento em TSA (Trypic Soy Agar) apenas da amostra 2, com posterior análise microscópica em coloração de Gram de três amostras da mesma placa de Petri. Todo esse processo foi executado por alunos da disciplina de forragicultura, orientados pelo docente responsável. Todas as etapas (picagem, compactação, armazenamento e vedação) foram registradas em forma de vídeo e posteriormente explicadas em sala de aula para a turma do $4^{\circ}$ período de Medicina Veterinária do IFAM - CMZL. Além de também serem apresentados a turma a amostragem de todo material ensilado obtido após a finalização do trabalho didático.

\section{Resultados e Discussão}

No decorrer da observação do experimento, notouse uma gradativa mudança na cor da forragem, variando do verde ao amarelo queimado. Como pode ser observado no Quadro 1, as mudanças de coloração não ocorreram de forma similar entre os exemplares (amostra 1 e amostra 2). 
Quadro 1: Exemplo de alterações macroscópicas observadas cronologicamente comparando amostras 1 e 2 na preparação experimental de silagem.

\begin{tabular}{|c|l|l|}
\hline PERÍODO & \multicolumn{1}{|c|}{ AMOSTRA 1 } & \multicolumn{1}{c|}{ AMOSTRA 2 } \\
\hline 24 horas & $\begin{array}{l}\text { Não apresentaram } \\
\text { alterações. }\end{array}$ & $\begin{array}{l}\text { Não apresentaram } \\
\text { alterações. }\end{array}$ \\
\hline Apresentou de maneira & $\begin{array}{l}\text { Não apresentava } \\
\text { uniformidade em sua } \\
\text { coloração, variando os } \\
\text { uniforme um tom } \\
\text { mais claro do que o } \\
\text { originalmente ensilado. }\end{array}$ & $\begin{array}{l}\text { dons de sua folhagem } \\
\text { em amarelos e verdes. }\end{array}$ \\
\hline 10 dias & Coloração estável. & $\begin{array}{l}\text { A forragem estava com } \\
\text { uma tonalidade mais } \\
\text { uniforme, porém mais } \\
\text { amarelada. }\end{array}$ \\
\hline 40 dias & $\begin{array}{l}\text { Manteve a estabilidade } \\
\text { da cor do material. }\end{array}$ & $\begin{array}{l}\text { Começou a apresentar } \\
\text { fungos em sua } \\
\text { forragem. }\end{array}$ \\
\hline coloração constante. & $\begin{array}{l}\text { Tons marrons e } \\
\text { enegrecidos. }\end{array}$ \\
\hline
\end{tabular}

As diferenças visuais entre os dois experimentos foram bem evidentes, com ocorrências distintas. As mudanças de coloração na amostra 1 ocorreram por influência dos ácidos presentes em concordância com os relatos de Kung et al. (2018), de forma gradativa seguindo a curva de crescimento bacteriano e queda do $\mathrm{pH}$ entre as fases fermentativas. $\mathrm{Na}$ amostra 2, por haver uma entrada de oxigênio, ocorreu oxidação das folhagens, além da decomposição de forma exponencial de decaimento parecida com o que foi concluído por Bambi et al. (2011). Observou-se diferença na continuidade das mudanças de coloração (Figura 1), sendo que após o $10^{\circ} \mathrm{dia}$, apenas a amostra 2 continuou o processo de amarelamento. Macêdo e Santos (2019), atribuem esse fato a uma ineficiência fermentativa com fins de conservação dessa forragem, com fase de estabilização não aparente. Esse resultado foi útil por demonstrar de forma visual e didática todo o processo que ocorreu na mudança de uma forragem natural para uma silagem, chegando a um fim bem distinto de cores entre as amostras 1 e 2 (Figura 2).

Figura 1: Após 10 dias, amostra 1 com cor inalterada e amostra 2 com áreas amareladas.

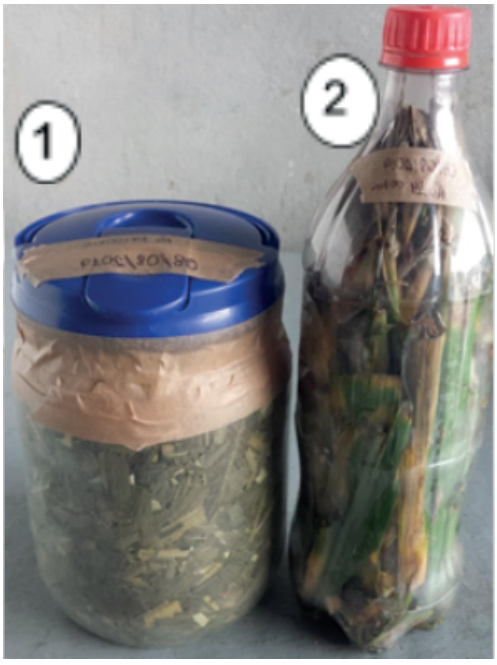

Fonte: Os autores (2019).
Figura 2: Após 40 dias, amostra 1 sem alterações macroscópicas e amostra 2 bastante enegrecida e deteriorada.

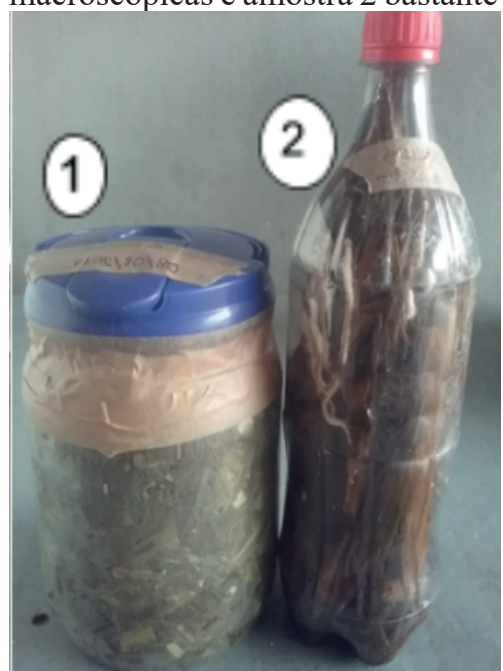

Fonte: Os autores (2019).

No $25^{\circ}$ dia observou-se na amostra 2 com seu conteúdo degradado e enegrecido, o surgimento de larvas (Figura 3 ) e no $30^{\circ}$ dia, manifestou o crescimento de corpos de frutificação de fungos (Figura 4), o que destacou a existência e influência da entrada de oxigênio na amostra 2, favorecendo esses organismos e tornando esta forragem totalmente inviável ao consumo dos animais.

Figura 3: Após 25 dias, amostra 2 apresentando larvas.

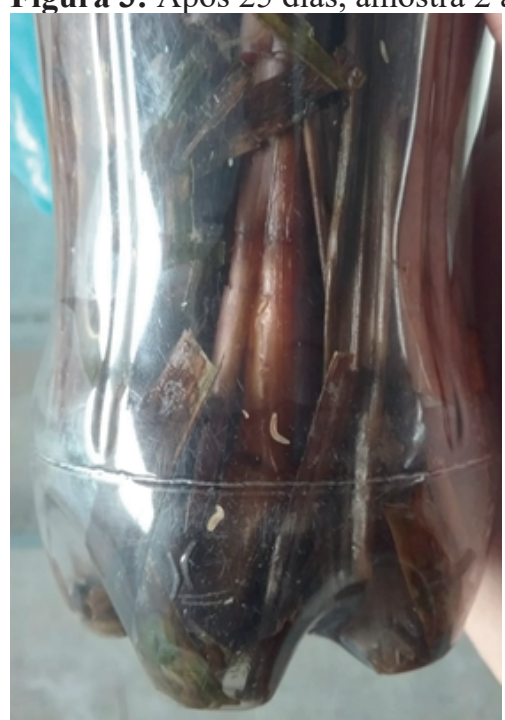

Fonte: Os autores (2019). 
Figura 4: Após 40 dias, amostra 2 apresentando cogumelos em seu interior.

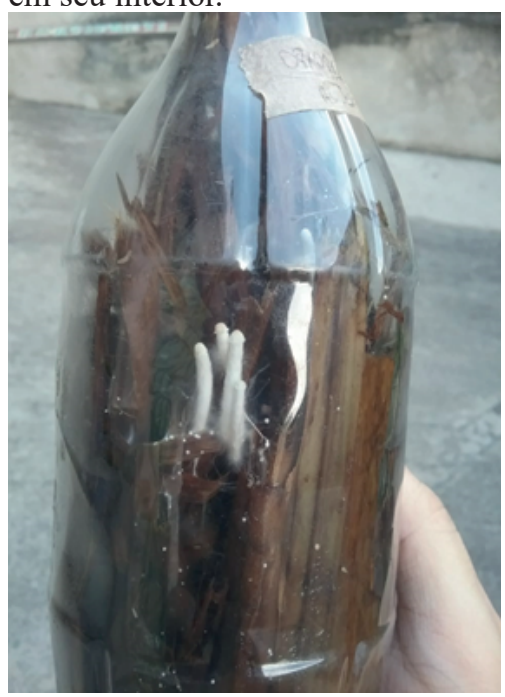

Fonte: Os autores (2019).

Foi realizada a abertura de ambos os silos após o período de análise, onde pôde-se constatar na amostra 1, uma camada superficial de coloração branca com focos enegrecidos que possuía um cheiro forte, diferente do observado em silagens com boa qualidade (Figura 5). Esse fato ocorreu devido alguma falha no processo onde proporcionou o crescimento de bolores e o provável Clostridium spp., ocasionando o seu odor pútrido (KUNG et al., 2018). Nesses casos, é recomendada a retirada dessa camada imprópria para o consumo animal (MUCK; HOLMES, 2005). Desta forma, a camada superior inadequada com esses fungos foi removida, tornando a amostra viável ao consumo.

Figura 5: Aspecto macroscópico da amostra após a abertura do mini silo.

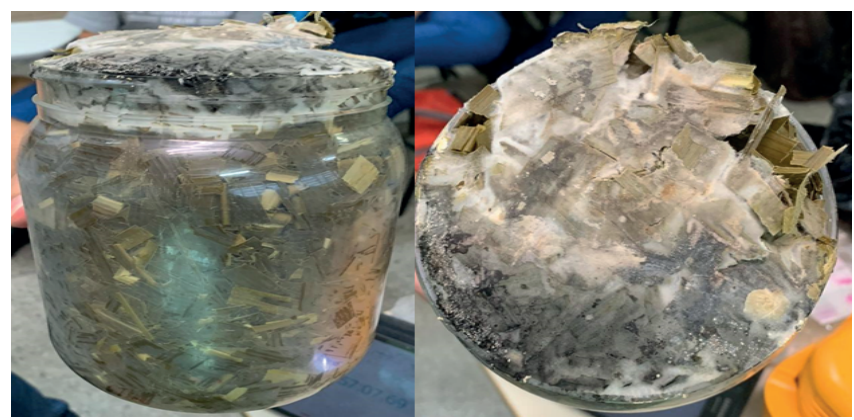

Fonte: Os autores (2019).

$\mathrm{Na}$ amostra 2, após a abertura foi realizado um plaqueamento para maior análise, o que resultou em três padrões de crescimento na placa: circular amarelo opaco, branco opaco desuniforme e um branco aveludado sem forma única. Com a análise microbiológica, foram observadas colônias de leveduras, bacilos e estreptococos gram negativos (Figura 6).
Figura 6: Análise microbiológica em placa de Petri e em microscópio eletrônico da amostra 2 após 40 dias, demostrando crescimento de colônias pertencentes à leveduras, bacilos, estreptococos e cocos gram negativos. Como é mostrado a seguir na figura 6.A e figura 6.B.

Figura 6.A - Plaqueamento em TSA (Trypic Soy Agar) em estufa $\left(30^{\circ} \mathrm{C}\right)$ durante 24 horas, onde observa-se crescimentos: circular amarelo opaco, branco opaco desuniforme e um branco aveludado sem forma única.

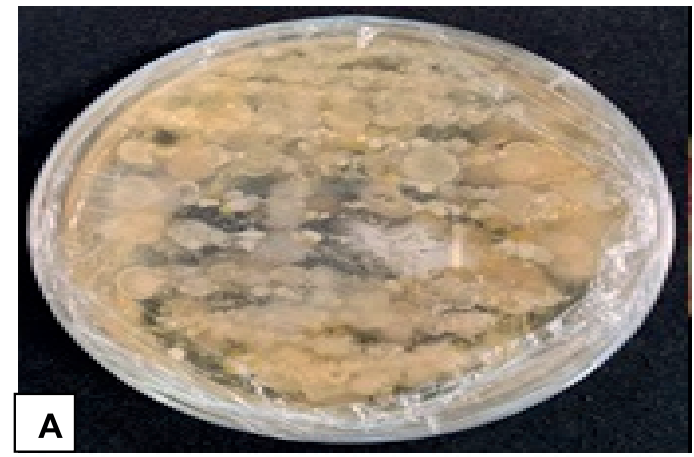

Fonte: Os autores (2019)

Figura 6.B - Visualização em microscopia com coloração de Gram e lente objetiva 100x. Observa-se variedades de microrganismos como leveduras, bacilos, estreptococos e cocos gram-negativos com pouca clareza de cada.

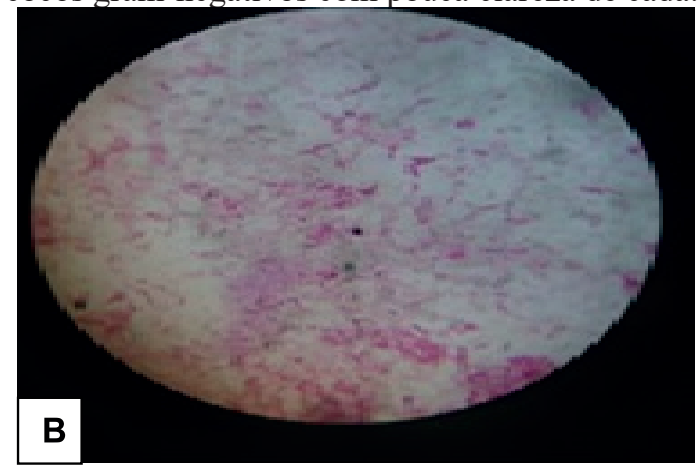

Fonte: Os autores (2019)

Assim como o crescimento de organismos dependentes de oxigênio se desenvolveram com facilidade na amostra 2, os microrganismos que se desenvolveram (Figura 5) foram de igual desconformidade com o que se consideraria esperar em uma silagem de qualidade (PAHLOW et al., 2003; MUCK, 2010). Logo, essa incidência de possíveis micotoxinas e esporos, trariam um grande risco aos animais que viessem a ingerir esse alimento. Além disso, haveria também um perigo de contaminação cruzada entre os produtos desses animais e as pessoas que consumissem sua carne e leite (GISMERVIK et al., 2015). Essa problemática foi discutida com os discentes, sendo notório o interesse e aprendizado dos mesmos.

\section{Conclusão}

O estudo da forragicultura tem se destacado cada vez mais devido ao seu impacto direto na produção animal, tendo em vista sua grande participação na economia 
brasileira e de outros países. Portanto, o conhecimento científico das características e etapas de produção corretas de plantas forrageiras e dos métodos de conservação das mesmas, tornam-se fundamentais para o melhor rendimento de produção, ganhos econômicos e, também, para o bemestar animal.

Por meio do ensaio demonstrativo realizado, observou-se que o uso de boas práticas na preparação da silagem, resulta em um produto de qualidade, constatando que o método de confecção está ligado diretamente com o seu resultado.

Além disso, a metodologia empregada mostrou-se bastante eficiente. Os resultados visuais tornaram os passos do processo de fabricação de ensilagem mais didáticos, de acordo com o feedback positivo dado pelos discentes e docentes que foram apresentados ao trabalho aqui exposto.

\section{Referências}

BAMBI, P. et al. Decomposição e redistribuição de nutrientes das folhas de espécies da floresta de transição Amazônia - Cerrado, MT. Ciência e Natura, Santa Maria, v. 33, n. 1, p. 17-31, 2011.

DIAS-FILHO, M. B. Diagnóstico das pastagens no Brasil. Belém, PA: Embrapa Amazônia. Oriental, 2014b. 36 p. (Embrapa Amazônia Oriental. Documentos, 402).

DOMINGUES, J. L. Uso de volumosos conservados na alimentação de equinos. Revista Brasileira de Zootecnia, Viçosa, v. 38, p. 259-269, Jul. 2009.

GISMERVIK, K. et al. Efeito de populações invasoras de lesmas (Arion vulgaris) na silagem de gramíneas. II: Qualidade microbiológica e segurança alimentar. Animal Feed Science and Technology, v. 199, p. 20-28, 2015.

KUNG, J. L. et al. Silage review: Interpretation of chemical, microbial, and organoleptic components of silages. Journal of Dairy Science, v. 101, p. 4020-4033, 2018.

MACÊDO, A. J. da S.; SANTOS, E. M. Princípios básicos para produção de silagem. Arq. Ciênc. Vet. Zool. UNIPAR, Umuarama, v. 22, n. 4, p. 147-156, out./dez. 2019.

MOREIRA, P. C. et al. Utilização de Capim-elefante para alimentação de bovinos. Estudos: vida e saúde, Goiânia, v. 35, n. 3, p. 429-449, maio/jun. 2008.

MUCK, R. E.; HOLMES, B. J. Factores affecting bag silo densities and losses. In: INTERNATIONAL SILAGE CONFERENCE, 14, 2005, Belfast. Proceedings... Belfast: Wageningen Academic Publishers, 2005, p. 245.

MUCK, R. E. Microbiologia silagem e seu controle por meio de aditivos. Revista Brasileira de Zootecnia, v. 39, p. 183-191, (supl. especial) 2010.

PAHLOW, G. et al. Microbiologia da ensilagem. In:
BUXTON, D. R.; MUCK, R. E.; HARRISON, J. H. (Eds.). Silage science and technology. 1. ed. Madison: American Society of Agronomy, 2003. p. 31-94.

PEREIRA, L. E. T.; BUENO, I. C. da S.; HERLING, V. R. Tecnologias para conservação de forragens: fenação $e$ ensilagem. São Paulo: Pirassununga, 2015. 47 p.

Recebido em: 30.09.2020

Aceito em: 15.07.2021 